\title{
Chinese Learners Learning Thai Language with an Application: Evidence from an Acoustic Study and a Perception Test
}

\author{
Phanintra Teeranon \\ School of Liberal Arts, University of Phayao, Thailand. \\ Email:tphanintra@hotmail.com
}

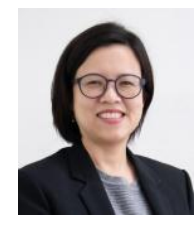

\begin{abstract}
This research analyzes the acoustic characteristics and conducts a perception test of Thai tones produced by Chinese learners learning Thai through the "Thai Tone Application". A comparison of Thai tones pronounced by 40 Chinese learners learning Thai at Nakhon Ratchasima Rajabhat University with 40 Thai native speakers was also conducted. The acoustic characteristics studied in this research were the fundamental frequencies analyzed with the Praat program version 6.0.9. The $F_{0}$ values were then converted to semitone values. Statistical analysis was used. The perception test was conducted before and after using the application. The results showed that the Thai Tone Application promoted better tone pronunciation and perception in Chinese learners learning Thai as a foreign language. After utilizing the Thai Tone Application with the Chinese learners, they could clearly pronounce the mid and the low tones, which is linguistically classified as the problematic level tones for Chinese learners. The application helped expedite contour tones such as the high tone and the rising tone, but not the falling tone. The minimal pair approach used to create the application was discussed.
\end{abstract}

Keywords: Acoustic, Perception, Chinese, Application, Thai.

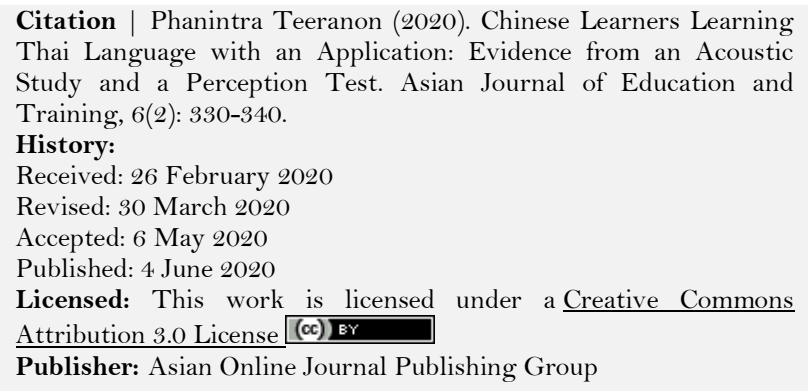

Citation | Phanintra Teeranon (2020). Chinese Learners Learning Thai Language with an Application: Evidence from an Acoustic Study and a Perception Test. Asian Journal of Education and Training, 6(2): 330-340.

History:

Received: 26 February 2020

Revised: 30 March 2020

Accepted: 6 May 2020

Published: 4. June 2020

Licensed: This work is licensed under a Creative Commons

Attribution 3.0 License (cc)

Publisher: Asian Online Journal Publishing Group

Funding: This study received no specific financial support.

Competing Interests: The author declares that there are no conflicts of interests regarding the publication of this paper.

Transparency: The author confirms that the manuscript is an honest, accurate, and transparent account of the study was reported; that no vital features of the study have been omitted; and that any discrepancies from the study as planned have been explained.

Ethical: This study follows all ethical practices during writing.

\section{Contents}

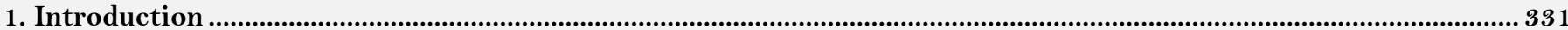

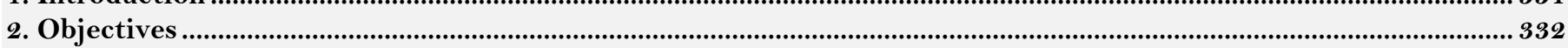

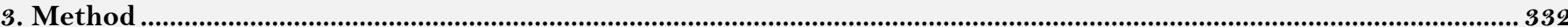

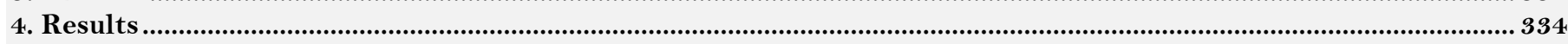

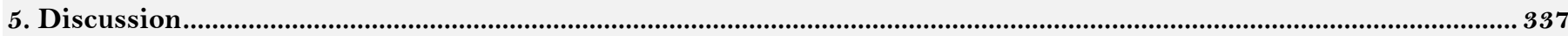

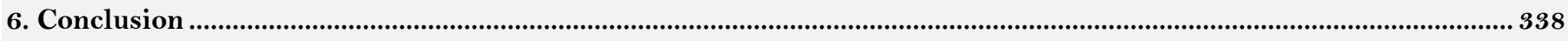

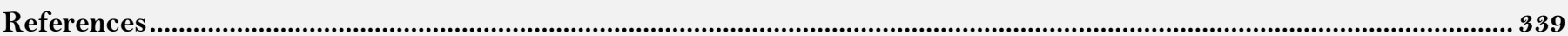




\section{Contribution of this paper to the literature}

This paper contributes to a variety of fields (linguistics, education, and technology) by providing quantifiable Thai tone evidence produced by Chinese learners learning Thai with Thai Tone Application, and the integration between these fields.

\section{Introduction}

Southeast Asian researchers have identified five major tones in the Thai language as seen in Figure 1: the mid33 , the low-2 1, the falling-31, the high-45, and the rising-323. In other words, they are significantly differentiating with its word meaning, e.g. [ruu $]+$ high/15 "to know" and [ruu $]+$ rising/323 "elegant". As consonants and vowels are equal in both words, the Thai tones serve to differentiate the meanings (Srisunthornthai, 2013). The relative fundamental frequency $\left(\mathrm{F}_{0}\right)$ of a voicing unit in a syllable is a major clue to measure phonemic tones in Thai. Acoustically, Thai tone shapes comprise the following:

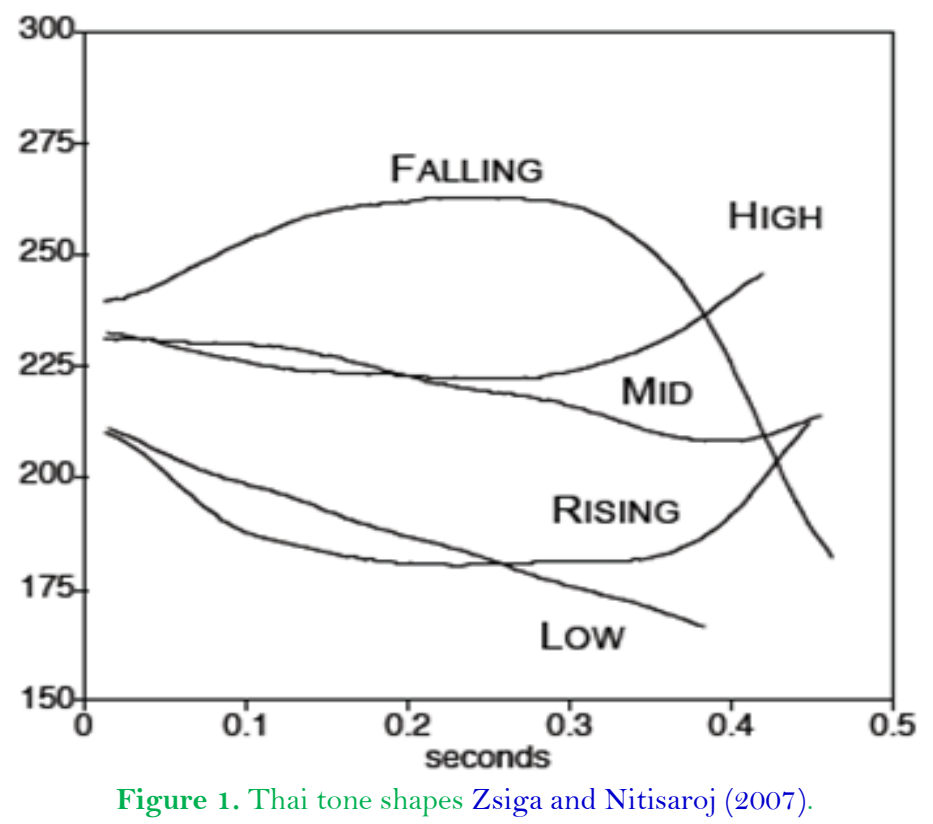

Five Thai tones (monosyllables) have been shown to be measurable in isolated words (Abramson, 1962; Abramson, 1975; Teeranon, 2007; Tumtavitikul, 1992) and a number of studies have investigated the tones' deviant shapes in connected speech (Panpraneet \& Onsuwan, 2013; Teeranon, 2002; Tingsabadh \& Deeprasert, 1997). Regarding the study of isolated words, researchers have categorized level tones and contour tones in Thai (Abramson, 1962; Abramson, 1975; Pittayaporn, 2007; Teeranon, 2007). However, in case of connected speech, linguists have investigated the factors affecting the shapes of Thai tones, which are reported to be steeper in tone shapes compared to isolated words (Tingsabadh \& Deeprasert, 1997). The results of previous research on Thai tones have potential benefits for pitch condition on speech recognition, tone language application, and teaching tonal languages, among others. It is likely that the factors affecting Thai tone shapes in various contexts include the stresses, as cited in Potisuk, Gandour, and Harper (1994) speaking rates, as cited in Gandour, Tumtavitikul, and Satthamnuwong (1999) the speaker's mother tongue and experience in practicing tones (Akkharasena, 2015; Intajamornrak, 2017) and even the hearing ability (e.g. deaf children and other speech disorders; (Suvanich, 2010; Tantibundhit et al., 2013; Teeranon \& Detchanarat, 2015).

Thai tones in speech can be identified by two common linguistics analyses: an acoustic analysis and a perception test. An acoustic analysis reflects the physiology of speech production, which is the rate of vocal folds vibration, while a perception test is defined as an auditory system to understand a language. An acoustic study of Thai tones and a Thai tone perception test were investigated by Abramson (1962); Abramson (1975) who found that differentiating mid and low tones was problematic for native Thai speakers. Later, Gandour and Dardarananda (1989) and Nasanee (2003) found that native Thai speakers barely differentiated high and rising tones. These results were in line with findings by Teeranon (2007). Recently, Thai tone perception was reported to be a factor likely to be contributing to Chinese learners' difficulty in writing Thai as a foreign language (Srisunthornthai, 2013).

It has long been stated that individuals who speak a non-tonal language unable to differentiate lexical tones comparing to those whose mother tongue are tonal language (Wang, Spence, Jongman, \& Sereno, 1999; Wayland \& Guion, 2004). Recently, however, both Akkharasena (2015) and Intajamornrak (2017) found that Thai tones are problematic for individuals who speak a tonal language as their mother tongue, as well as for those studying a tonal language but whose mother tongue is toneless. For learners who speak other languages, some Thai tone levels, such as the mid and low tones, can be quite confusing, as well as certain contour tones, such as the high tone, the falling tone and the rising tone. Kaan, Barkley, Bao, and Wayland (2008) has found the falling tone in Thai sensitive to the speakers with non-tone language (English). Similarly, for Americans learners learning to speak Mandarin, the contour tone is the most difficult to pronounce. Guo and Tao (2008) report that of the four tones in Mandarin Chinese, namely Tone 1 (a level), Tone 2 (a rising), Tone 3 (a mid falling-rising), and Tone 4 (a falling), Chinese (Mandarin) Tone 3 (a contour tone) is the most difficult tone for American learners learning Mandarin. This finding is in line with findings by Dong, Tsubota, and Dantsuji (2013) who found that Tone 3 (a contour tone) was most problematic for Japanese learners (non-tonal language) learning Mandarin. On the contrary, Putthasatien (2017) found that the most difficult tone for Nakhon Ratchasima Rajabhat University Chinese students was the low tone which is classified as a level tone in Thai. The sample participants of Putthasatien (2017) were students from the People's Republic of China (PRC) and their mother tongue was 
Mandarin Chinese. It has been shown that after two years of studying the language using an exercise handbook developed by a linguistics process, all tone-related pronunciation problems are solved among Chinese learners, except the low tone. However, the exercise handbook aiming to train Chinese learners studying Thai tones of Putthasatien (2017) supports the findings of Kaan et al. (2008) which have mentioned that the sensitivity of $F_{0}$ onset differences between the falling tone and the mid tone in Thai was suppressed by language training. The findings of Putthasatien (2017) has also supported (Meesat, 2015) who has found that the mid and the low tone in Thai are hard for the Chinese learners, but this mid and the low tone problem in the Chinese learning Thai can be solved by using the Somatically-Enhanced Approach which contains clapping, humming, and using gestures.

Apart from lecturers, training and other learning environments, previous research on Thai tones has suggested the following tools to promote learners' proficiency in studying Thai tones: 1) a handbook on Thai tones (Chicharoen, 2011; Luangthongkham, 2015; Putthasatien, 2017) and 2) the Somatically-Enhanced teaching method (Meesat, 2015) and 3) applications for practicing Thai tones. The applications for studying Thai language were included in the Thai government's education policy to promote e-learning in the Thai 4.0 era. However, the approach used to create Thai tone contents in the previous tools is unclear. Crosbie, Holm, and Dodd (2005) has pointed out the importance of approach advocated for speech practice. Traditionally, in clinical linguistics for speech disorders, one common approach used is minimal pairs that a phoneme differs in one position (e.g. pig-big, bat-bag) (Baker \& McLeod, 2004; Dodd et al., 2008). The extent of the speech disorders progress is claimed to depend on the word minimal pairs (Dean \& Howell, 1986; Dodd et al., 2008).

The latest application in Thailand called the "Thai Tone Application (TTA)" has been created based on previous linguistics research and the minimal pairs approach. Its contents are mainly focused on practicing the minimal pairs of problematic tones for language learners, namely the mid-low, low-falling, and high-rising tones (e.g. [khaa $]+$ low tone "galangal"-[khaa $]+$ falling tone "to kill").

In the past few decades, technology has increasingly been used to enhance learners' language communication. This increased use of technology can mostly be observed in teaching and learning English as a foreign language, as shown by previous findings by Chen, Mao, and Liu (2014) and Shadiev, Hwang, and Huang (2017). Chen et al. (2014) considered English proficiency scores after using the application, while Shadiev et al. (2017) were concerned with the use of technology-assisted based learning to promote other skills, such as critical thinking (Gafni, Achituv, \& Rachmani, 2017; Saisuwan, 2012).

Therefore, this study aims to investigate whether the Thai low tone which is a problematic tone after using the exercise handbook in Putthasatien (2017) will be solved and affected by the Thai Tone Application with minimal pairs approach or not. The methods are to analyze the acoustic characteristics (tone shape) and conduct a perception test of Thai tones produced by Chinese learners learning Thai through the "Thai Tone Application". The use of technology plus minimal pairs approach to enhance learners' language communication for Thai as a foreign language and its limitations are discussed. Then, all Thai tones produced by Chinese learners learning Thai through the "Thai Tone Application" are benchmarked with standard Thai produced by native Thai speakers.

\section{Objectives}

1. To analyze the acoustic characteristics and conduct a perception test of Thai tones produced by Chinese learners learning Thai with the "Thai Tone Application".

2. To compare the acoustic characteristics of Thai tones produced by Chinese learners learning Thai using the "Thai Tone Application" with Thai tones produced by native Thai speakers.

3. To compare the perception of Thai tones in the Chinese learners learning Thai before and after using the "Thai Tone Application".

\section{Method}

\subsection{Participants and Language Information}

This study used linguistics methods in the acoustic analysis and perception test. Prior to describing both the acoustic and the perception test method, the language data and participant criteria in the study were the following:

The language data used for the test tokens were drawn from standard Thai. The Thai language has a collection of 18 consonants: /p, $\mathrm{p}^{\mathrm{h}}, \mathrm{b}, \mathrm{t}, \mathrm{t}^{\mathrm{h}}, \mathrm{d}, \mathrm{k}, \mathrm{k}^{\mathrm{h}}, \mathrm{m}, \mathrm{n}, \mathrm{\textrm {y }}, \mathrm{r}, \mathrm{f}, \mathrm{s}, \mathrm{h}, \mathrm{t} \mathrm{t}, \mathrm{t} \mathrm{6}^{\mathrm{h}}, \mathrm{j} /$; and nine monopthongal vowels: / $\mathrm{l}, \mathrm{l}, \mathrm{v}, \varepsilon, \leftrightarrow, \mathrm{o}$, E, $\alpha, \square /$, all with vowel length distinctions. Its five tones are mid-33, low-21, falling-31, high-45, and rising-323. However, all the test words contained the vowel $/ \alpha \alpha /$ to avoid the effects of $\mathrm{F}_{0}$ differences in vowels.

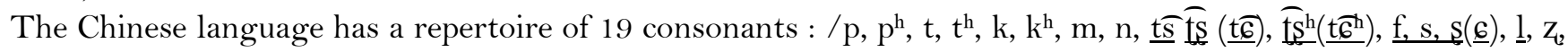
$\varnothing /$; five vowels / i u a ia ua o io uae e ie $\varepsilon$ iє ei uei au iau əu iəu iu ãy iãy uãy ẽ iẽ uẽ on ion/; and four tones: Tone 1 (a high level -55), Tone 2 (a rising-35), Tone 3 (a mid falling-rising-214), and Tone 4 (a falling-51) (Guo \& Tao, 2008). Though there is one more tone in an unstressed syllable which is the neutral tone (Zhang, 2006) this study counts on the Chinese tones in the stressed syllables.

For the acoustic study, 40 Chinese participants in the age range of 19-21 were selected. There were 10 males and 30 females. All were studying the first year of their major in Thai at Nakhon Ratchasima Rajabhat University, Thailand.

The participants were selected by Thai language grading scores to ensure that all had a broadly equal level of proficiency. Their first language was standard Chinese.

Native Thai speakers were also selected to elicit benchmark data for comparing Thai tone shapes. Forty native Thai speakers aged 19-21 with perfect articulation were recruited.

Three sets of test tokens were created using the / $\alpha \alpha /$ vowel with a variety of initial consonants to control the effect of initial consonant voicing upon tone shapes, as shown in Table 1. 
Table-1. Thai words for recording.

\begin{tabular}{|c|c|c|}
\hline Set 1 & Set 2 & Set 3 \\
\hline$[\kappa \eta \alpha \alpha]+$ mid "to be stuck" & {$[v \alpha \alpha]+$ mid "rice field" } & {$[\phi \alpha \alpha]+$ mid "a note" } \\
\hline$[\kappa \eta \alpha \alpha]+$ low "galangal" & $\begin{array}{l}{[(v \square \mathfrak{l}+\text { high }) \cdot(\underline{v \alpha \alpha}+\text { low })]} \\
\text { "custard apple" }\end{array}$ & $\begin{array}{l}{[\phi \alpha \alpha]+\text { low "palm (of the hand), }} \\
\text { sole (of the foot)" }\end{array}$ \\
\hline$[\kappa \eta \alpha \alpha]+$ falling "value" & {$[v \alpha \alpha]+$ falling "face" } & {$[\phi \alpha \alpha]+$ falling "scum" } \\
\hline$[\kappa \eta \alpha \alpha]+$ high "to trade" & {$[v \alpha \alpha]+$ high "aunt" } & {$[\phi \alpha \alpha]+$ high "sky" } \\
\hline$[\kappa \eta \alpha \alpha]+$ rising "leg" & {$[v \alpha \alpha]+$ rising "thick" } & {$[\phi \alpha \alpha]+$ rising "pot cover" } \\
\hline
\end{tabular}

\subsection{An Acoustic Analysis}

The Chinese learners and native Thai speakers were asked to produce Thai tones in isolated words five times. The first three pronunciations were selected, as the fourth and the fifth tone pronunciation were likely to be affected by their intonation. The Chinese learners the recording twice for both their pre-test and post-test. The native Thai speakers' tones were recorded only once.

\subsubsection{Pre-Test for Chinese Learners}

After listing the appropriate test tokens that were voiceless and voicing initials to avoid contextual effects to $\mathrm{F}_{\mathrm{o}}$ ), the participants were asked to pronounce each test word in isolation with a moderate tempo. The number of total test tokens was 1,800 test tokens/words (40 participants $\mathrm{x} 3$ sets $\mathrm{x} 3$ times $\mathrm{x} 5$ tones). The Praat program version 6.2.09 was used to segment each vocalization and analyze the $\mathrm{F}_{0}$ of isolated words. The frequencies at five time points for each vowel were selected for measurement at 0\%, 25\%, 50\%, 75\%, and 100\%. Microsoft Excel 2008 was used to analyze and plot graphs illustrating the overall mean $(\mathrm{x} \square)$ of $\mathrm{F}_{\mathrm{o}}$ tones.

The participants were asked to determine 50 minimal pairs of test tokens in the Thai Tone Application for five weeks based on a study by Phiboon (2016) which reported that five weeks is a suitable time period for data collection of in-class research. Every 20 minutes before dismissing the class, participants were given a chance to study Thai tones through the app. The participants were trained to use the app by their teachers.

In the app, there are 50 tone minimal pairs both in the isolated form (word form) and in the sentence form. The Chinese learners could listen to the pronunciation in the application and check their tone pronunciation and compare it to a live correction. The scores were shown after using the application.

The application was tested for reliability by three experts. An evaluation form was created based on the technology acceptance model (TAM). The experts were asked to rate the following three aspects: innovations, process, and innovation values. A Likert three-point scale (Kumar, 2014) was used as follows:

$$
\begin{array}{lll}
\text { O-1.66 means the application value is low } \\
1.67-2.33 & \text { means the application value is moderate } \\
2.34-3.00 & \text { means the application value is high }
\end{array}
$$

The Thai Tone Application had a mean score of 2.75 , which was rated as a high value.

\subsubsection{Post-Test for Chinese Learners}

After studying the application for five weeks, the test tokens were pronounced with a moderate tempo. The Praat program version 6.2.09 was used to segment the isolated words. The frequencies at five time points for each vowel were selected for measurement at $0 \%, 25 \%, 50 \%, 75 \%$, and $100 \%$.

\subsubsection{An Acoustic Analysis for Native Thai Speakers}

Native Thai speakers were asked to pronounce isolated words. The first three out of five pronunciations were selected. Each word was pronounced with a moderate tempo. The number of total test tokens was 1,800 test tokens/words (40 participants x 3 sets x 3 times x 5 tones). The Praat program version 6.2.09 was used to analyze sounds and the graphs illustrated with the overall mean $(\mathrm{x} \square)$ of tones $\mathrm{F}_{\mathrm{o}}$ were analyzed and plotted.

\subsection{A Perceptual Experiment}

For the perception test, the Chinese learners were asked to listen to test sounds pronounced by a Thai language lecturer at Mae Fah Luang University and match the stimulus sounds they heard with the sounds in the choice. There were 10 major stimulus sound items, with five choices in the examination paper: Choice 1 (Mid tone sound), Choice 2 (low tone sound), Choice 3 (falling tone sound), Choice 4 (high tone sound), and Choice 5 (rising tone sound). Table 2 shows an example examination paper used in the perception test.

Table-2. An example of perception examination paper.

\begin{tabular}{c|c|c|c|c|c}
\hline Table-2. An example of perception examination paper. \\
\hline Sound Entry & $\begin{array}{c}\text { Choice 1 } \\
\text { Mid }\end{array}$ & $\begin{array}{c}\text { Choice 2 } \\
\text { Low }\end{array}$ & $\begin{array}{c}\text { Choice 3 } \\
\text { Falling }\end{array}$ & $\begin{array}{c}\text { Choice 4 } \\
\text { High }\end{array}$ & $\begin{array}{c}\text { Choice 5 } \\
\text { Rising }\end{array}$ \\
\hline $1[\kappa \eta \alpha \alpha]+$ Mid & {$[\kappa \eta \alpha \alpha]$} & {$[\kappa \eta \alpha \alpha]$} & {$[\kappa \eta \alpha \alpha]$} & {$[\kappa \eta \alpha \alpha]$} & {$[\kappa \eta \alpha \alpha]$} \\
\hline $2[\kappa \eta \alpha \alpha]+$ Low & {$[\kappa \eta \alpha \alpha]$} & {$[\kappa \eta \alpha \alpha]$} & {$[\kappa \eta \alpha \alpha]$} & {$[\kappa \eta \alpha \alpha]$} & {$[\kappa \eta \alpha \alpha]$} \\
\hline $3[\kappa \eta \alpha \alpha]+$ Falling & {$[\kappa \eta \alpha \alpha]$} & {$[\kappa \eta \alpha \alpha]$} & {$[\kappa \eta \alpha \alpha]$} & {$[\kappa \eta \alpha \alpha]$} & {$[\kappa \eta \alpha \alpha]$} \\
\hline $4[\kappa \eta \alpha \alpha]+$ High & {$[\kappa \eta \alpha \alpha]$} & {$[\kappa \eta \alpha \alpha]$} & {$[\kappa \eta \alpha \alpha]$} & {$[\kappa \eta \alpha \alpha]$} & {$[\kappa \eta \alpha \alpha]$} \\
\hline $5[\kappa \eta \alpha \alpha]+$ Rising & {$[\kappa \eta \alpha \alpha]$} & {$[\kappa \eta \alpha \alpha]$} & {$[\kappa \eta \alpha \alpha]$} & {$[\kappa \eta \alpha \alpha]$} & {$[\kappa \eta \alpha \alpha]$} \\
\hline $6[v \alpha \alpha]+$ Mid & {$[v \alpha \alpha]$} & {$[v \alpha \alpha]$} & {$[v \alpha \alpha]$} & {$[v \alpha \alpha]$} & {$[v \alpha \alpha]$} \\
\hline $7[v \alpha \alpha]+\operatorname{Low}$ & {$[v \alpha \alpha]$} & {$[v \alpha \alpha]$} & {$[v \alpha \alpha]$} & {$[v \alpha \alpha]$} & {$[v \alpha \alpha]$} \\
\hline $8[v \alpha \alpha]+$ Falling & {$[v \alpha \alpha]$} & {$[v \alpha \alpha]$} & {$[v \alpha \alpha]$} & {$[v \alpha \alpha]$} & {$[v \alpha \alpha]$} \\
\hline $9[v \alpha \alpha]+$ High & {$[v \alpha \alpha]$} & {$[v \alpha \alpha]$} & {$[v \alpha \alpha]$} & {$[v \alpha \alpha]$} & {$[v \alpha \alpha]$} \\
\hline $10[v \alpha \alpha]+$ Rising & {$[v \alpha \alpha]$} & {$[v \alpha \alpha]$} & {$[v \alpha \alpha]$} & {$[v \alpha \alpha]$} & {$[v \alpha \alpha]$} \\
\hline
\end{tabular}


For the perceptual experiment, 40 participants were asked to listen to each stimulus and choose an answer from five choices. Following this, the perception matrix was drawn.

\subsection{Data Analysis}

All of the Fo values measured in 3.2.1-3.2.3 were converted to semitone values to diminish the voice variations among the participants. The formula used was as follows:

$\mathrm{ST}=12 * \operatorname{LOG}(\mathrm{C} 21 / \mathrm{X}) / \operatorname{LOG}(2)$, where $\mathrm{X}$ means the fewest Fo values in each tone.

Then, Microsoft Excel 2008 was used to analyze and plot graphs illustrating the overall mean of the Fo tones.

Statistical descriptions drawn for this study were analyzed using the mean, percentages, and a Pair Sample ttest. A p-value higher than $0.05(>0.05)$ is considered not statistically significant for confidence interval of $95 \%$.

Given Abramson (1997) and Thavisak (2004) findings that $0 \%$ to $25 \%$ of the syllable onset are able to differentiate their tone perception, the semitone values at two onset points of time $(0 \%-25 \%)$ for each tone were averaged for mean scores. The analyzed data was then used to compare 1) the semitone values of each tone produced by Chinese learners in the pre-test and post-test (before and after using the application), 2) the semitone values of Thai tones produced by Chinese learners before using the application to each tone produced by the native Thai speakers and 3) the semitone values of Thai tones produced by Chinese learners after using the application to the tones produced by the native Thai speakers, and 4) tone perception was presented in the format of confusion matrix table.

\section{Results}

\subsection{Acoustic Analysis}

To understand the extent to which the application enhanced the Chinese learners' ability to differentiate midlow tones, low-falling tones, and high-rising tones, an acoustic analysis and perception test were redeveloped, as shown in Figure 2.

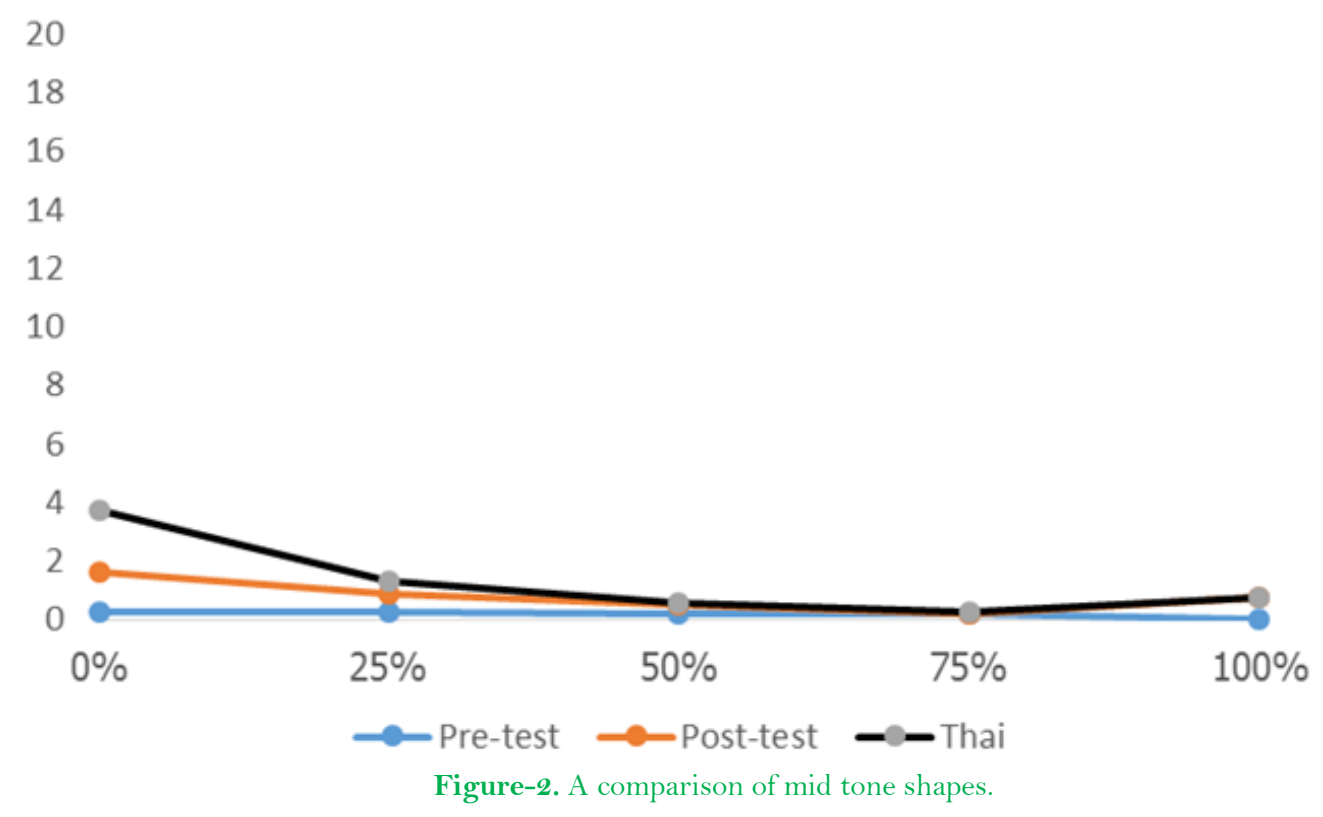

Table-3. A comparison of the semitone values of the mid tone produced by Chinese learners before using the application to native Thai speakers.

\begin{tabular}{l|c|c|c}
\hline & $\begin{array}{c}\text { Average of the semitone values (ST) } \\
\text { at the onset (0\%-25\%) }\end{array}$ & S.D. & p-value \\
\hline Pre-test by Chinese learners & 0.18 & 5.19 & 0.415 \\
\hline Native Thai & 0.52 & 6.80 & \\
\hline
\end{tabular}

Table-4. A comparison of the semitone values of the mid tone produced by Chinese learners after using the application to native Thai speakers.

\begin{tabular}{l|c|c|c}
\hline & $\begin{array}{c}\text { Average of the semitone values (ST) } \\
\text { at the onset }(\mathbf{0} \%-\mathbf{2 5 \%})\end{array}$ & S.D. & p-value \\
\hline $\begin{array}{l}\text { Post-test by Chinese } \\
\text { learners }\end{array}$ & 0.60 & 4.72 & 0.868 \\
\hline Native Thai & 0.52 & 6.16 & \\
\hline
\end{tabular}

As shown in the comparison of Thai mid tone shapes in Figure 2 it is clear that after using the Thai Tone Application, the Chinese learners' pronunciation of mid tones was improved in comparison to before using the application. The first three points of the post-test graph are closer to the tone shape of the Thai pronunciation. It can be seen that the mid tone shapes pronounced by the Chinese speakers were less contoured compared to those of the native Thai speakers. However, there was a small rise found in the end of the tone shape in the post-test.

Tables 3 and 4 show that when comparing the semitone values of the mid tones produced by the Chinese learners before using the application to those produced by the native Thai speakers, there was no statistical significance. Similarly, when comparing the semitone values of the mid tones produced by the Chinese learners 
after using the application to those of the native Thai speakers, there was also no significance. The statistical analysis confirmed that the mid tone shapes of Chinese learners were similar to those produced by the native Thai speakers. However, after using the application, the mid tone shapes were more similar to those of the Thai speakers.

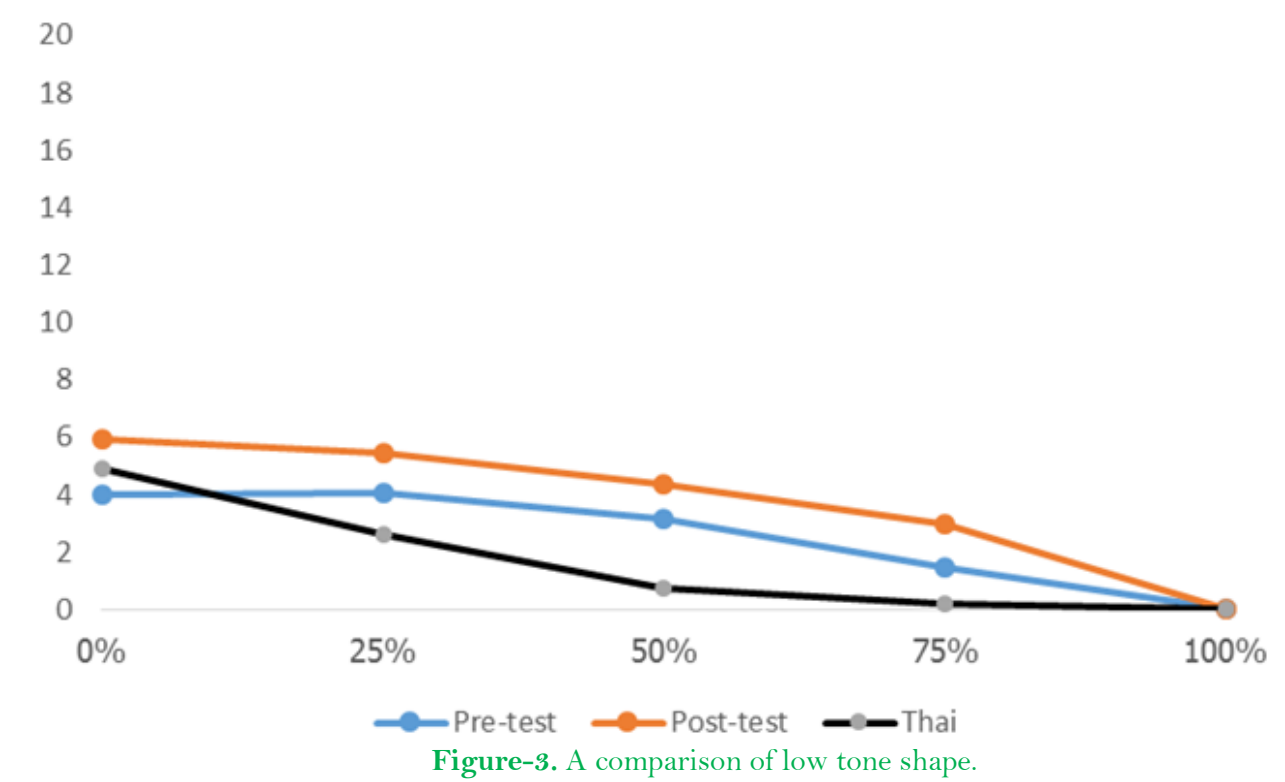

Table-5. A comparison of the semitone values of the low tone produced by Chinese learners before using the application to native Thai speakers.

\begin{tabular}{l|c|c|c}
\hline & $\begin{array}{c}\text { Average of the semitone values (ST) } \\
\text { at the onset (0\%-25\%) }\end{array}$ & S.D. & p-value \\
\hline Pre-test by Chinese learners & 2.53 & 6.38 & 0.512 \\
\hline Native Thai & 1.71 & 5.22 & \\
\hline
\end{tabular}

Table-6. A comparison of the semitone values of the low tone produced by Chinese learners after using the application to native Thai speakers.

\begin{tabular}{l|c|c|c}
\hline & $\begin{array}{c}\text { Average of the semitone values (ST) } \\
\text { at the onset }(\mathbf{0 \% - 2 5 \% )}\end{array}$ & S.D. & p-value \\
\hline Post-test by Chinese learners & 3.72 & 7.46 & 0.189 \\
\hline Native Thai & 1.71 & 4.81 & \\
\hline
\end{tabular}

Figure 3 shows the comparison of Thai low tone shapes. Here, the findings were similar to those of the mid tone shapes. It was found that after using the Thai Tone Application, the Chinese learners could produce low tones more effectively than before using the application. The first three points of the graph show the tone shapes were closer to those of the native Thai speakers.

Tables 5 and 6 shows that when comparing the semitone values of the low tone produced by the Chinese learners before using the application to those produced by the native Thai speakers, the results were not statistically significant. Similarly, when comparing the semitone values of the low tone produced by the Chinese learners after using the application to those of the native Thai speakers, there was also no significance. The statistical analysis confirmed that the low tone shapes of the Chinese learners was similar to those produced by the native Thai speakers. After using the application, the low tone shape of Chinese is a bit different from that of the Thai speakers.

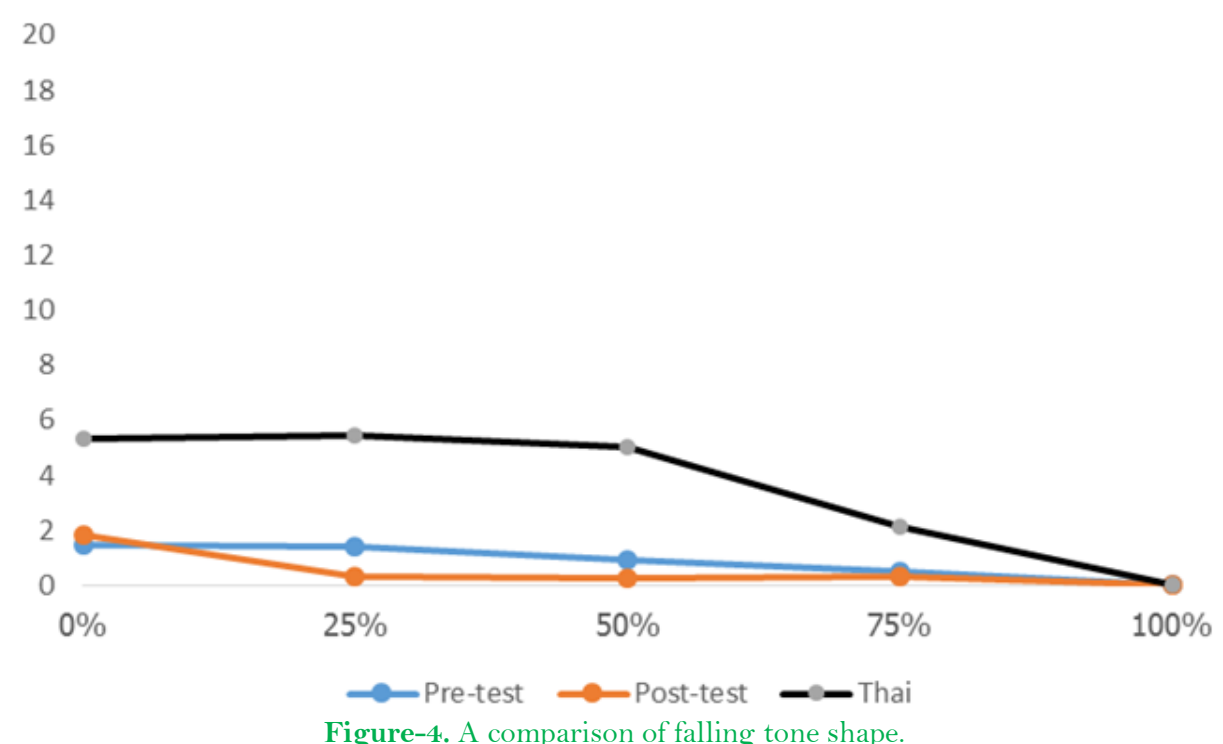

Figure-4. A comparison of falling tone shape. 
Table-7. A comparison of the semitone values of the falling tone produced by Chinese learners before using the application to native Thai speakers.

\begin{tabular}{l|c|c|c}
\hline & $\begin{array}{c}\text { Average of the semitone values (ST) } \\
\text { at the onset }(\mathbf{0} \%-\mathbf{2 5} \%)\end{array}$ & S.D. & p-value \\
\hline Pre-test by Chinese learners & 0.86 & 8.71 & $0.049^{*}$ \\
\hline Native Thai & 3.69 & 7.23 & \\
\hline Note* means statistically significance (sig) & &
\end{tabular}

Table-8. A comparison of the semitone values of the falling tone produced by Chinese learners after using the application to native Thai speakers.

\begin{tabular}{l|c|c|c}
\hline & $\begin{array}{c}\text { Average of the semitone values (ST) } \\
\text { at the onset (o\%-25\%) }\end{array}$ & S.D. & p-value \\
\hline Post-test by Chinese learners & 0.56 & 8.85 & \multirow{2}{*}{$0.020^{*}$} \\
\cline { 1 - 3 } Native Thai & 3.69 & 6.30 & \\
\hline Note** means statistically significance (sig) &
\end{tabular}

Note:* means statistically significance (sig)

Figure 4 shows a comparison of falling tone shape. The shape was at a higher level for half the duration, before gradually dropping for the native Thai speakers. However, the falling tone shape was less contoured for the Chinese learners. Here, the falling tone shape after using the app was similar to the pre-test.

Tables 7 and 8 show that when comparing the semitone values of the falling tone produced by the Chinese learners before using the application to those produced by the native Thai speakers, there was a statistical significance. Similarly, when comparing the semitone values of the falling tone produced by the Chinese learners after using the application to those of the native Thai speakers, there was a statistical significance. The statistical analysis confirmed that the falling tone shapes of Chinese learners were similar to those produced by the Thai speakers. After using the application, the falling tone shapes of Chinese shows more variety in tone shape than those of the Thai speakers.

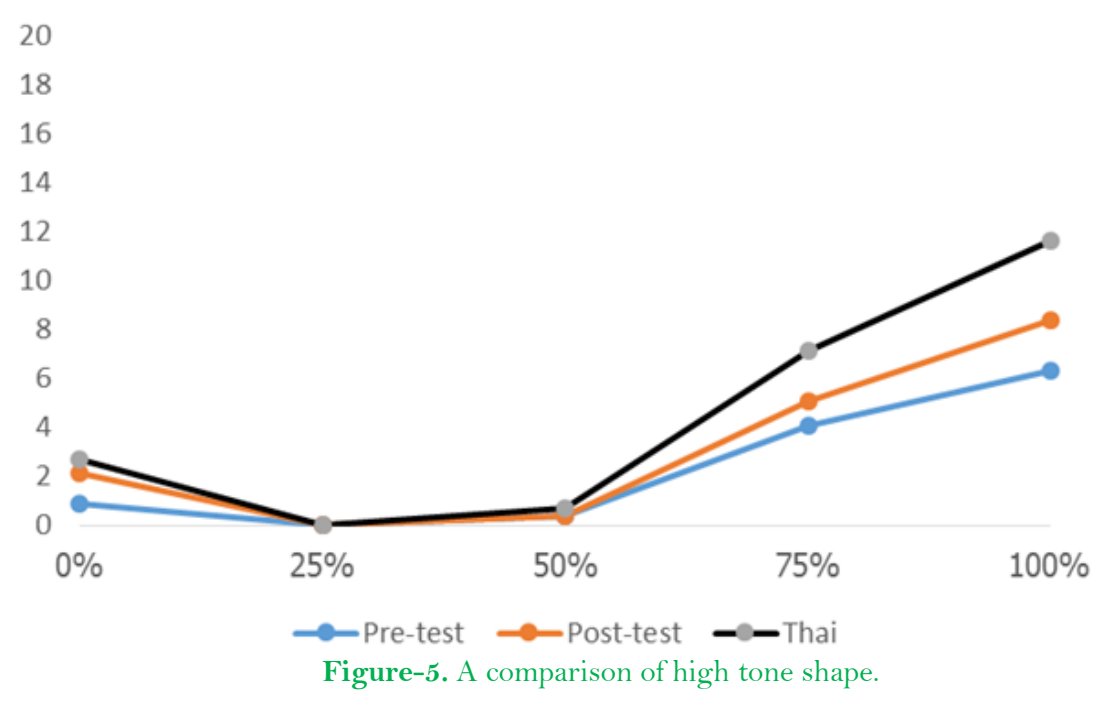

Table-9. A comparison of the semitone values of the high tone produced by Chinese learners before using the application to native Thai speakers.

\begin{tabular}{l|c|c|c}
\hline & $\begin{array}{c}\text { Average of the semitone values (ST) } \\
\text { at the onset }(\mathbf{0} \% \mathbf{- 2 5} \%)\end{array}$ & S.D. & p-value \\
\hline Pre-test by Chinese learners & 2.32 & 9.48 & 0.448 \\
\hline Native Thai & 1.22 & 3.77 & \\
\hline
\end{tabular}

Table-10. A comparison of the semitone values of the high tone produced by Chinese learners after using the application to native Thai speakers.

\begin{tabular}{l|c|c|c}
\hline & $\begin{array}{c}\text { Average of the semitone values (ST) } \\
\text { at the onset (o\%-25\%) }\end{array}$ & S.D. & p-value \\
\hline Post-test by Chinese learners & 0.87 & 7.20 & 0.642 \\
\hline Native Thai & 1.22 & 5.08 & \\
\hline
\end{tabular}

The high tone shape in Figure 5 fell and was relatively steady before rising in the native Thai speakers. The Thai speakers' pre-test and post-test were both similar in shape compared to that of the Chinese learners; however, the pitch level was different in the post-test, where it was slightly lower than the Thai speakers, while the pre-test pitch level was the lowest.

Tables 9 and 10 show that when comparing the semitone values of the high tone produced by the Chinese learners prior to using the application to those produced by the native Thai speakers, the results did not show a statistical significance. Similarly, when comparing the semitone values of the high tone produced by the Chinese learners after using the application to those of the native Thai speakers, there was also no significance. The statistical analysis confirmed that the high tone shapes of the Chinese learners were similar to those produced by the Thai speakers. After using the application, the high tone shapes of the Chinese learners were closer to those of the Thai speakers. 


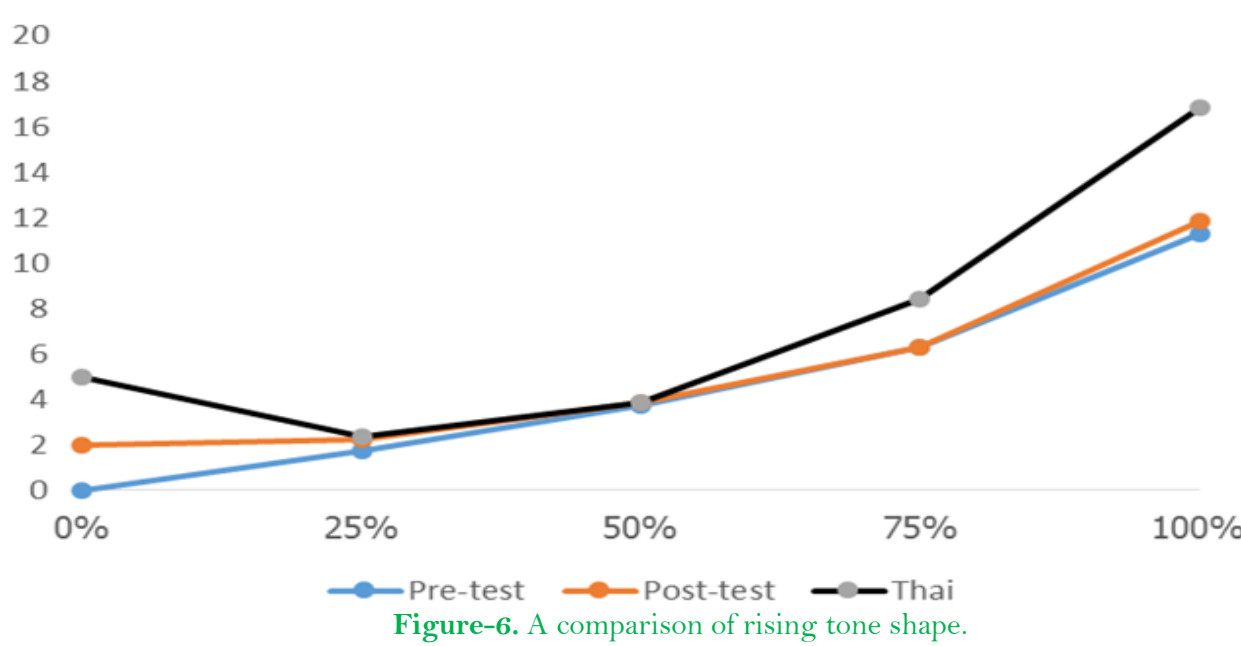

Table-11. A comparison of the semitone values of the rising tone produced by Chinese learners before using the application to native Thai speakers.

\begin{tabular}{l|c|c|c}
\hline & $\begin{array}{c}\text { Average of the semitone values (ST) } \\
\text { at the onset (0\%-25\%) }\end{array}$ & S.D. & p-value \\
\hline Pre-test by Chinese learners & 4.60 & 5.07 & 0.275 \\
\hline Native Thai & 2.06 & 4.35 & \\
\hline
\end{tabular}

Table-12. A comparison of the semitone values of the rising tone produced by Chinese learners after using the application to native Thai speakers.

\begin{tabular}{l|c|c|c}
\hline & $\begin{array}{c}\text { Average of the semitone values (ST) } \\
\text { at the onset (0\%-25\%) }\end{array}$ & S.D. & p-value \\
\hline Post-test by Chinese learners & 0.62 & 9.02 & \multirow{2}{*}{0.187} \\
\hline Native Thai & 2.06 & 8.16 & \\
\hline
\end{tabular}

One surprising finding was that the shape of the rising tone produced by the native Thai speakers fell and was relatively steady before rising see Figure 6 . However, the tone shape in the pre-test and post-test were similar and were less contoured. Here, the shape was very similar to previous high tone shapes found in Abramson (1962).

Tables 11 and 12 show that when comparing the semitone values of the rising tone produced by the Chinese learners before using the application to those produced by the native Thai speakers, there was no statistical significance. Similarly, when comparing the semitone values of the rising tone produced by the Chinese learners after using the application to those of the native Thai speakers, there was no statistical significance. The statistical analysis confirmed that the rising tone shape of Chinese learners was similar to those produced by the Thai speakers.

\subsection{Perception Test}

A perception test was conducted to confirm the acoustic results. Table 13 shows the results of tone identification of the Chinese learners learning Thai before using the application, and Table 14 shows the results of the tone identification of Chinese learners learning Thai after using the application.

\begin{tabular}{c|c|c|c|c|c}
\multicolumn{2}{c}{ Table-13. Thai tone perception matrix of Chinese learners learning Thai before using the Thai Tone Application. } \\
\hline Tones & Mid & Low & Falling & High & Rising \\
\hline Mid & $95 \%$ & $5 \%$ & $0 \%$ & $0 \%$ & $0 \%$ \\
\hline Low & $15 \%$ & $83 \%$ & $3 \%$ & $0 \%$ & $0 \%$ \\
\hline Falling & $1 \%$ & $28 \%$ & $71 \%$ & $0 \%$ & $0 \%$ \\
\hline High & $0 \%$ & $0 \%$ & $0 \%$ & $58 \%$ & $62 \%$ \\
\hline Rising & $0 \%$ & $0 \%$ & $0 \%$ & $70 \%$ & $30 \%$ \\
\hline
\end{tabular}

Table-14. Thai tone perception matrix of Chinese learners learning Thai after using the Thai Tone Application.

\begin{tabular}{c|c|c|c|c|c}
\hline Tones & Mid & Low & Falling & High & Rising \\
\hline Mid & $99 \%$ & $1 \%$ & $0 \%$ & $0 \%$ & $0 \%$ \\
\hline Low & $5 \%$ & $95 \%$ & $0 \%$ & $0 \%$ & $0 \%$ \\
\hline Falling & $0 \%$ & $19 \%$ & $81 \%$ & $0 \%$ & $0 \%$ \\
\hline High & $0 \%$ & $0 \%$ & $0 \%$ & $88 \%$ & $12 \%$ \\
\hline Rising & $0 \%$ & $0 \%$ & $0 \%$ & $10 \%$ & $90 \%$ \\
\hline
\end{tabular}

Table 13 shows that before using the application, the mid tones were identified as low tones by $5 \%$ of participants, and this decreased to $1 \%$ after practicing with the Thai Tone Application see Table 14. The identification of low tones also improved from $83 \%$ to $95 \%$, in addition to improvement in falling tone identification.

The identification of high tones and rising tones was low before using the application, but was higher than after using the application.

\section{Discussion}

In the acoustic study, the Thai Tone Application containing minimal pairs approach (e.g.the word pairs of the low tone vs. the falling tone, [khaa $]+$ low tone "galangal"-[khaa $]+$ falling tone "to kill" etc.) improved the Chinese learners' ability to produce both level tones and contour tones. The acoustic characteristics of Thai tones produced 
by Chinese learners learning Thai using the Thai Tone Application are similar to that of the tones produced by the native Thai speakers. However, the t-tests in Tables 2-12 shown that low tone (level tone) and falling tone (contour tone) were particularly difficult for Chinese learners, because after using the Thai Tone Application, both tone shapes were different to those of the native Thai speakers.

In the perception test, after using the application, the Chinese learners can differentiate between the mid tone and the low tone. The identification rates of the high tone and the rising tone after using the application are also higher than before using the application.

The results settle the argument of whether Thai tones are problematic for individuals who speak a tonal language as their mother tongue, as well as for those studying a tonal language but whose mother tongue is toneless (Akkharasena, 2015; Intajamornrak, 2017) and whether level tones or contour tones are problematic for students learning the Thai language (Schaefer \& Darey, 2013; Schaefer \& Darey, 2014).

It is shown that those whose mother tongue is a tonal language has the problem in producing and differentiating Thai tones. They also reveal that both the level and contour tones in the Thai language are difficult for foreign language speakers learning Thai.

This findings are consistent with the claim of Meesat (2015) and Putthasatien (2017) that the problematic tones of the Chinese learners learning Thai tones are the level tones, namely the mid tone [33] and the low tone [21]. This is due to the mid and the low tone shapes in Thai language displays the most similar patterns. The mid tone starts at the mid pitch level and remains steady pitch throughout the end of the syllable, and the low tone starts at a bit lower pitch level comparing to the mid tone and remains steady pitch throughout the end of the syllable. The results of the perception test correspond to previous Thai tone perception results, in which both a high tone and a rising tone were difficult to identify. Research has shown that native Thai speakers find it hard to differentiate between high tones and rising tones (Gandour \& Dardarananda, 1989; Nasanee, 2003). This is because the high tone shape has been changed from high level to high-falling-rising which is similar to the rising tone shape as found in Teeranon (2007).

High and rising tones in Chinese have been identified as [55] and [35], while in Thai, a high tone is [45] and a rising tone is [323]. It was clear that the two time points for each tone of $0 \%$ and $25 \%$ represented the critical range for tone perception, as found in L-Thongkum (1991) where the registers analyzed were clear vowels, clearcreaky vowels, breathy vowels, and clear-breathy vowels. The results of L-Thongkum (1991) showed that clear vowels tended to have a lower $\mathrm{F}_{0}$ than breathy vowels at $0 \%-30 \%$ of the vowel duration. The $\mathrm{F}_{\mathrm{o}}$ was higher after $30 \%$ of the vowel duration, consistent with research by Abramson, Theraphan, and Nye (2004), Thavisak (2004) and Watkins (2002). This is unlike Hong Kong Cantonese, Khouw and Ciocca (2007) who found that tone perception depends on the final quarter of the tone bearing-unit. This means, the tone perception can depend on either the first part or the final part of the tone, and it is varied from language to language.

The results also showed that the application helped Chinese learners studying Thai to improve their listening skills. The results are in line the previous studies conducted by Kim (2013) and Suwantarathip and Orawiwatnakul (2015) they showed that those who used the application tended to show improved English listening skills.

It was found that using the Thai Tone Application enabled the Chinese learners learning Thai tones to differentiate the mid-low tones, low-falling tones, and high-rising tones. Therefore, it is suggested that the Thai Tone Application with minimal pairs approach is an effective learning tool to improve the pronunciation of Thai tones. It was also effective in improving the Chinese learners' perception. The results significantly support findings by the clinical linguistics studies using minimal pairs approach to therapy (Baker \& McLeod, 2004; Crosbie et al., 2005; Dodd et al., 2008). In addition, the present study confirms that the minimal pairs approach can be applied to the suprasegmental levels. The results are also in line with Haggag (2018) and Saran, Seferoglu, and Cagiltay (2009) who show that the application is beneficial for training speaking skills.

However, one of the surprising findings in this study was that after using the application, the differentiation of falling tones-31 showed less improvement than other minimal pairs. Putthasatien (2017) found that all Thai tones apart from the low tone can be learned by studying an exercise handbook for Chinese learners studying Thai at Nakhon Ratchasima Rajabhat University. However, in this study, it was shown that the Thai Tone Application could boost the pronunciation of the low tone by Chinese learners, but not the falling tone. Recently, Meesat (2015) who has found that the mid and the low tone in Thai are hard for the Chinese learners, but this mid and the low tone problem in the Chinese learning Thai can be solved by using the Somatically-Enhanced Approach which contains clapping, humming, and using gestures. Meesat (2015) has also reported that the falling tone can be enhanced by the Somatically-Enhanced Approach. Therefore, it is suggested that the mediums of instruction have to be used in align with the teaching methods for better Thai tone production and perception.

The application is an augmentation of teaching method. It helps the process of learning, but it is a doubt whether it can replace the instructor or not.

The present study has some strengths, including the use of integrated methods (i.e.the minimal pairs approach in the application, and linguistic research methods) that enabled this study to show another perspectives on the acoustic study and the perception test of Thai tones. The results can be generalized because of the larger number of participants in this study. However, the period of using Thai Tone Application was relatively short which might affect the learning process of Chinese learners learning Thai tones. Further investigation is clearly need to determine the long period of using the application to enhance tone production and perception.

\section{Conclusion}

In conclusion, Thai tones are problematic for individuals who speak a tonal language as their mother tongue as well as those who speak non-tonal language as their mother tongue. A combination of tradition minimal pairs approach with the application can promote both speech production and perception of the Chinese learners learning Thai tones. However, it is doubt whether the application can replace the instructor or not. 


\section{References}

Abramson, A. S. (1962). The vowels and tones of Standard Thai: Acoustical measurements and experiments. Bloomington, Inc: Indiana University Research Center in Anthropology, Folklore and Linguistics, Publication No. 20.

Abramson, A. S. (1997). The Thai tonal space. In A. S. Abramson (Ed.), Southeast Asian linguistics studies in honor of Vichin Panupong (pp. 1-10). Bangkok: Chulalongkorn University Press.

Abramson, A. S. (1975). The tone of central Thai: Some perceptual experiments. In J. G. Harris and J. R. Chamberlain, (Eds), Studies in Thai Linguistics in Honor of William J. Gedney (pp. 1-16). Bangkok: Central Institute of English Language Office of State Universities.

Abramson, A. S., Theraphan, L., \& Nye, P. W. (2004). Voice register in Suai (Kuai): An analysis of perceptual and acoustic data. Phonetica, 61(2-3), 147-171.Available at: https://doi.org/10.1159/000082561.

Akkharasena, K. (2015). Production of Bangkok Thai tones by native speakers of Burmese and Urdu. Vacana Journal of Language and Linguistics, 3(2), 1-23.

Baker, E., \& McLeod, S. (2004). Evidence-based management of phonological impairment in children. Child Language Teaching and Therapy, 20(3), 261-285.Available at: https://doi.org/10.1191/0265659004ct2750a.

Chen, M., S., Mao, S., \& Liu, Y. (2014). Big data: A survey. Mobile Networks and Applications, 19(2), 171-209.

Chicharoen, S. (2011). Tonal diversion practice exercises for Thai language learners as a foreign language. An Unpublished M.Ed. Thesis, Graduate School, Srinakharinwirot University, Bangkok.

Crosbie, S., Holm, A., \& Dodd, B. (2005). Intervention for children with severe speech disorder: A comparison of two approaches. International Journal of Language $\&$ Communication Disorders, 40(4), 467-491.Available at: https://doi.org/10.1080/13682820500126049.

Dean, E., \& Howell, J. (1986). Developing linguistic awareness: A theoretically based approach to phonological disorders. British Journal of Disorders of Communication, 21(2), 223-238.Available at: https://doi.org/10.3109/13682828609012279.

Dodd, B., Crosbie, S., McIntosh, B., Holm, A., Harvey, C., Liddy, M., . . Rigby, H. (2008). The impact of selecting different contrasts in phonological therapy. International Journal of Speech-Language Pathology, 10(5), 334-345.Available at: https://doi.org/10.1080/14417040701732590.

Dong, Y., Tsubota, Y., \& Dantsuji, M. (2013). Difficuties in perception and pronunciation of Madarin Chinese Disyllabic word tone acquisition: A study of some Japanese university students. PACLIC-27. Paper presented at the 27th Pacific Asia Conference on Language, Information, and Computation.

Gafni, R., Achituv, D. B., \& Rachmani, G. J. (2017). Learning foreign languages using mobile applications. Journal of Information Technology Education: Research, 16(1), 301-317.Available at: https://doi.org/10.28945/3855.

Gandour, J., Tumtavitikul, A., \& Satthamnuwong, N. (1999). Effects of speaking rate on Thai tones. Phonetica, 56(3-4), 123-134.Available at: https://doi.org/10.1159/000028447.

Gandour., J. T., \& Dardarananda, R. (1989). A case study of abnormal phonological development in Thai. Linguistics of the Tibeto-Burman Area, 12(1), 156-185.

Guo, L., \& Tao, L. (2008). Tone production in Mandarin Chinese by American students: A case study. Paper presented at the Proceedings of the 20th North American Conference on Chinese Linguistics (NACCL-20).

Haggag, H. (2018). Teaching phonetics using a mobile-based application in an EFL context. European Scientific Journal, ESJ, 14(14), 189204.Available at: https://doi.org/10.19044/esj.2018.v14n14p189.

Intajamornrak, C. (2017). Thai tones produced by tonal and non-tonal language speakers: An acoustic study. Manusya: Journal of Humanities, $20(2), 1-26$.

Kaan, E., Barkley, C., Bao, M., \& Wayland, R. (2008). Thai lexical tone perception in native speakers of Thai, English and Mandarin Chinese: An event-related potentials training study. BMC Neuroscience, 9(1), 1-17.

Khouw, E., \& Ciocca, V. (2007). Perceptual correlates of Cantonese tones. Journal of Phonetics, 35(1), 104-117.

Kim, H. S. (2013). Emerging mobile apps to improve English listening skills. Multimedia-Assisted Language Learning, 16(2), 11-30.

Kumar, R. (2014). Research methodology London: SAGE Pub.

L-Thongkum, T. (1991). An instrumental study of Chong registers. In J. H. C. S Davidson (Ed.), Austroasiatic Languages Essays in Honour of H. L. Shorto. School of Oriental and African Studies (pp. 141-160): University of London.

Luangthongkham, T. (2015). A teacher's handbook on Thai pronunciation practice model conducted under the electronic research and development training project for solving the problems of pronunciation and Spoken Thai Language. Bangkok: Phabpim Printing House.

Meesat, P. (2015). Somatically-enhanced approach (SEA) in intensive Thai course for academic purposes. An Unpublished Ph.D. Thesis of the University of Canberra, Canberra.

Nasanee, K. (2003). Thai tones pronounced by speakers using Trachea-Esophageal: Phonetic analysis and perception testing. An Unpublished M. A. Thesis, Department of Linguistics, Faculty of Arts, Chulalongkorn University, Bangkok.

Panpraneet, P., \& Onsuwan, C. (2013). Perception of lexical tones in Thai children of different age group. Paper presented at the The 23rd Annual Meeting of the Southeast Asian Linguistics Society (SEALS), Chulalongkorn University, Bangkok, Thailand.

Phiboon, S. (2016). Research-based learning. An Unpublished Report on Research-Based Learning at KM Hotel, Phayao 4-5 July 2016, Thailand.

Pittayaporn, P. (2007). Directionality of tone change. In J. Trouvain and W. J. Barry (Eds). Paper presented at the Proceedings of the 16th International Congress of Phontic Sciences (ICPhS XVI). Saarbrücken, Germany: Saarland University.

Potisuk, S., Gandour, J. T., \& Harper, M. (1994). Fo correlates of stress in Thai. Linguistics of the Tibeto-Burman Area, $17(2)$, 1 -27.

Putthasatien, K. (2017). The development of Thai tone pronunciation exercise: A case study of Chinese student, NRRU. Journal of Language, Religion and Culture, 6(1), 1-12.

Saisuwan, K. (2012). The development of an integrated mobile learning model using collaborative problem-solving method to enhance undergraduate students' inquiring mind. An Unpublished M. A. Thesis Chulalongkorn University, Bangkok.

Saran, M., Seferoglu, G., \& Cagiltay, K. (2009). Mobile assisted language learning: English pronunciation at learners' fingertips. Egitim Arastirmalari-Eurasian Journal of Educational Research, 34(34), 97-114.

Schaefer, V., \& Darey, I. (2013). Cross-linguistic perception of Thai tones is shaped by the functional prominence of lexically-contrastive pitch in L1. Paper presented at the Paper Presented at New Sounds 2013, Montreal, Quebec Canada.

Schaefer, V., \& Darey, I. (2014). Pitch prominence matters: Perception of Thai tones by Seoul Korean and Kyungsang Korean speakers. Concordia Working Papers in Applied Linguistics 5. Paper presented at the Proceeding of the International Symposium on the Acquisition of Second Language Speech.

Shadiev, R., Hwang, W.-Y., \& Huang, Y.-M. (2017). Review of research on mobile language learning in authentic environments. Computer Assisted Language Learning, 30(3-4), 284-303.Available at: https://doi.org/10.1080/09588221.2017.1308383.

Srisunthornthai, J. (2013). The effect of the mother tongue on Thai writing skill of the Chinese students. Language and Linguistics, 32(1), 90121.

Suvanich, R. (2010). Thai tone perception in deaf adults who use cochlear implants. An Unpublished M. A. Thesis, Mahidol University, Bangkok.

Suwantarathip, O., \& Orawiwatnakul, W. (2015). Using mobile-assisted exercises to support students vocabulary skill development. TOJET: The Turkish Online Journal of Educational Technology, 14(1), 163-171.

Tantibundhit, C., Onsuwan, C., Klangpornkun, N., Phienphanich, P., Saimai, N., Saimai, T., . . . Wutiwiwatchai, C. (2013). Lexical tone perception in Thai normal-hearing adults and those using hearing aids: A case study. Paper presented at the Proceedings of the 14th Annual Conference of the International Speech Communication Association (InterSpeech), Lyon, France.

Teeranon, P. (2007). The change of Standard Thai high tone: An acoustic study and a perceptual experiment. SKASE Journal of Theoretical Linguistics, 4(3), 1-17.

Teeranon, P. (2002). Rhythmic units and tonal variation in Thai. Manusya: Journal of Humanities, 5(2), 16-29.

Teeranon, P., \& Detchanarat, T. (2015). An acoustic analysis of Thai tones produced by normal and hearing loss children. Journal of Liberal Arts, 15(2), $213-231$. 
Thavisak, A. (2004). Fo behavior of vowels influenced by aspirated and unaspirated initials in Southeast Asian Languages: implications for Tonogenesis theories. In S. Burusphat (Ed.). Paper presented at the Papers from the Eleventh Annual Meeting of the Southeast Asian Linguistics Society. Tempe Arizona, Arizona State University, Program for Southeast Asian Studies.

Tingsabadh, K., \& Deeprasert, D. (1997). Tones in Standard Thai connected speech. In A. S. Abramson (Ed.), Southeast Asian Linguistics Studies in Honour of Vichin Panupong. Bangkok: Chulalongkorn University Press.

Tumtavitikul, A. (1992). Consonant onsets and tones in Thai. An Unpublished Ph.D. Dissertation, University of Texas at Austin.

Wang, Y., Spence, M. M., Jongman, A., \& Sereno, J. A. (1999). Training American listeners to perceive Mandarin tones: Transfer to production. The Journal of the Acoustical Society of America, 105(2), 1095-1095.Available at: https://doi.org/10.1121/1.422940.

Watkins, J. (2002). The phonetics of Wa: Experimental phonetics, phonology, orthography and sociolinguistics. Canberra: Research School of Pacific and Asian Studies, The Australian National University.

Wayland, R. P., \& Guion, S. G. (2004). Training English and Chinese listeners to perceive Thai tones: A preliminary report. Language Learning, 54(4), 681-712.Available at: https://doi.org/10.1111/j.1467-9922.2004.00283.x.

Zhang, F. (2006). The teaching of Mandarin prosody: A somatically-enhanced approach for second language learners. An Unpublished Ph.D. Thesis of the University of Canberra, Canberra.

Zsiga, E., \& Nitisaroj, R. (2007). Tone features, tone perception, and peak alignment in Thai. Language and Speech, 50(3), 343-383.Available at: https://doi.org/10.1177/00238309070500030301. 